\title{
A rare cause of lytic lesion: the brown tumors
}

\begin{abstract}
Introduction: Brown tumor is a tumor-like lesion that represents the terminal stage of the bone remodeling process in prolonged hyperparathyroidism and has an overall incidence of $3 \%$. It may not be distinguishable from other osteolytic lesions of malignancy. We illustrate a case of primary hyperparathyroidism with brown tumour which was initially mistaken for malignant disease.

Case report: A 64-year-old female patient with a medical history of dyslipidemia repeated acute pancreatitis and retrobulbar neuritis was referred to our department for evaluation of hypercalcemia. The association with a hypogammaglobulinemia gave rise to the initial diagnosis of humoral hypercalcemia of multiple myeloma. The radiological evaluation of the skeleton showed an isolated lytic lesion on the humerus. No electrophoretic signs of monoclonal secretion in the blood or urine were found. Nevertheless, laboratory investigations revealed a constellation of primary hyperparathyroidism. Computed tomography localized a right parathyroid adenoma, which was surgically removed. Also, we concluded that the humeral lesion was in fact a Brown tumor.
\end{abstract}

Conclusion: This case reinforces the need to consider brown tumor of hyperparathyroidism in the differential diagnosis of an osteolytic lesion with hypercalcemia.
Volume II Issue 6 - 2019

Maroua Khaloui, Fatma Daoud, Imène Rachdi, Mehdi Somai, Hana Zoubeidi, Zohra Aydi, Nedia Hammami,Wided Hizem, Besma Ben Dhaou, Fatma Boussema

Department of Internal medicine, Habib Thameur Hospital, Tunis El Manar University,Tunisia

Correspondence: Imène Rachdi, Department of Internal medicine, Habib Thameur Hospital, Tunis El Manar University, Ali Ben Ayed Street, 1089 Tunis, Tunisia,

Email rachdi.imenel@gmail.com

Received: October 25, 2019 | Published: November 15, 2019

Keywords: brown tumors, hyperparathyroidism, osteolytic lesions

\section{Introduction}

Primary hyperparathyroidism (PHPT) is the third most common endocrine disease after diabetes and thyroid disease with the highest incidence in postmenopausal women. ${ }^{1}$ Osteitis fibrosa cystica or Brown Tumors represent a rare clinical manifestation of hyperparathyroidism dependent bone pathology, reported in approximately $3 \%$ of patients with prolonged PHPT, ${ }^{2,3}$ and correspond to radiologically osteolytic lesions with well-defined borders in different parts of the skeleton. We illustrate a case of PHPT with brown tumor, which was initially mistaken for malignant disease.

\section{Case report}

A 64-year-old woman was referred to our department for evaluation of hypercalcemia. Her medical history was significant for dyslipidemia, repeated acute pancreatitis and retrobulbar neuritis. She had diffuse skeletal pain for which she tried analgesics and anti-inflammatory medication with minimal relief. Her physical examination was unremarkable.

The presence of hypogammaglobulinemia gave rise to the initial diagnosis of humoral hypercalcemia of multiple myeloma. Subsequently, a radiological evaluation of the skeleton was undertaken and showed a well-defined lytic lesion at the middle of the humerus. The absence of anaemia or renal insufficiency and the absence of electrophoretic signs of monoclonal secretion in the blood or urine eliminate this diagnosis. The others biochemical indices confirmed the diagnosis of PHPT: hypercalcemia at $11.9 \mathrm{mg} / \mathrm{dL}(8.4$ $10.2 \mathrm{mg} / \mathrm{dL})$, serum hypophosphatemia at $1.54 \mathrm{mg} / \mathrm{dL}(2.7-4.5 \mathrm{mg} /$ $\mathrm{dL})$, and elevated parathyroid hormone rate at $584 \mathrm{pg} / \mathrm{mL}(10-88 \mathrm{pg} /$ $\mathrm{mL})$. We noted a serum $25 \mathrm{OHD}$ deficiency at $8.4 \mu \mathrm{g} / \mathrm{L}(30-70 \mathrm{~g} / \mathrm{L})$. At subsequent radiological work-up, both ultrasonography and computed tomography of her neck revealed a right parathyroid adenoma. We concluded posterior that the humeral lesion was in fact a Brown tumor (Figure 1).

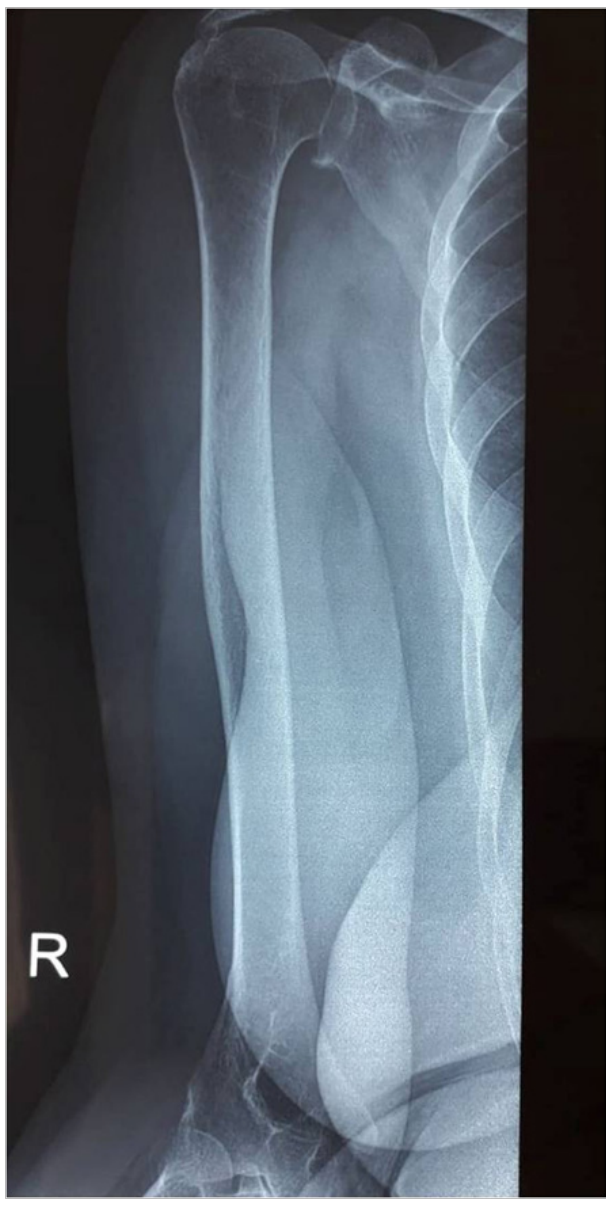

Figure I Ultrasonography and computed tomography of neck. 


\section{Discussion}

Bone is a classic target organ in PHPT, and common skeletal changes involve generalized osteopenia, ${ }^{4}$ bone resorption, bone cysts and Brown tumors. The name "Brown Tumor" derives from the color, which is caused by the vascularity, haemorrhage and deposits of hemosiderin. ${ }^{5}$

They can occur in any location but are most common in the ribs, clavicle and pelvis. ${ }^{6,7}$ Our case is characterized by an atypical and unique localization in humerus. As in our observation, on radiological examination they appear as osteolytic lesions with well-defined borders. ${ }^{8}$ It is noteworthy that its radiological and histopathological features may be mistaken for other bony pathologies., ${ }^{3,-12}$

A wrong diagnosis in such cases could lead to subjecting the patient to unnecessary radical procedures with severe and irreversible squeal. ${ }^{13}$ Distinguishing between brown tumor of primary hyperparathyroidism and malignancy is made readily by the concomitant measurement of parathyroid hormone, which in primary hyperparathyroidism will be markedly elevated.

\section{Conclusion}

This case emphasizes the need of considering initially primary hyperparathyroidism in the exploration of hypercalcemia even when radiographic lytic lesions are present.

\section{Acknowledgments}

None.

\section{Competing interests}

The authors declare there is no conflict of interest.

\section{Contributorship}

Khaloui M, Daoud F: Preparation of manuscript; All authors edited the manuscript and accepted its final form.

\section{Funding}

This research did not receive any specific grant from funding agencies in the public, commercial, or not-for-profit sectors.

\section{Patient consent for publication}

Not required.

\section{Data sharing statement}

No data are available.

\section{References}

1. Pappu R, Jabbour SA, Regianto AM, et al. Musculoskeletal manifestations of primary hyperparathyroidism. Clin Rheumatol. 2016;35(12):3081-3087.

2. Bandeira F, Cusano NE, Silva BC, et al. Bone disease in primary hyperparathyroidism. Arq Bras Endocrinol Metabol. 2014;58(5):553561

3. Ullah E, Ahmad M, Ali SA, et al. Primary hyperparathyroidism having multiple Brown tumors mimicking malignancy. Indian $J$ Endocrinol Metab. 2012;16(6):1040-1042.

4. Sonmez E, Tezcaner T, Coven I, et al. Brown tumor of the thoracic spine: first manifestation of primary hyperparathyroidism. J Korean Neurosurg Soc. 2015;58(4):389-392.

5. Pavlovic S, Valyi-Nagy T, Profirovic J, et al. Fine-needle aspiration of brown tumor of bone: Cytologic features with radiologic and histologic correlation. Diagn Cytopathol. 2009;37(2):136-139.

6. Hruska KA, Teitelbaum SL. Renal osteodystrophy. $N$ Engl $J$ Med. 1995;333(3):166-174.

7. Yousif J, Birkeland AC, Spector ME. A young man with hypercalcemia. JAMA Otolaryngol Head Neck Surg. 2017;143(3):311-312.

8. Sandoval MA. Radiographical appearance of osteitis fibrosa cystica in primary hyperparathyroidism before and after parathyroidectomy. $B M J$ Case Rep. 2013.

9. Bassler T, Wong ET, Brynes RK. Osteitis fibrosa cystica simulating metastatic tumor. An almost-forgotten relationship. Am J Clin Pathol. 1993;100(6):697-700.

10. Kalathas T, Kalatha T, Boultoukas E. Brown tumors; a possible pitfall in diagnosing metastatic disease. Hell J Nucl Med. 2010;13(1):15-17.

11. Panagopoulos A, Tatani I, Kourea HP, et al. Osteolytic lesions (brown tumors) of primary hyperparathyroidism misdiagnosed as multifocal giant cell tumor of the distal ulna and radius: a case report. $J$ Med Case Rep. 2018;12(1):176.

12. Phulsunga RK, Parghane RV, Kanojia RK, et al. Multiple brown tumors caused by a parathyroid adenoma mimicking metastatic bone disease from giant cell tumor. World J Nucl Med. 2016;15(1):56-58.

13. Misiorowski W, Czajka-Oraniec I, Kochman M, et al. Osteitis fibrosa cystica-a forgotten radiological feature of primary hyperparathyroidism. Endocrine. 2017;58(2):380-385. 